\title{
Long-term regional bond strength of three MMA-based adhesive resins in simulated vertical root fracture
}

\author{
Hamid NURROHMAN ${ }^{1,2}$, Toru NIKAIDO ${ }^{1}$, Alireza SADR ${ }^{2}$, Tomohiro TAKAGAKI ${ }^{1}$, Shuzo KITAYAMA ${ }^{1}$, Masaomi IKEDA ${ }^{1}$, \\ Kanchana WAIDYASEKERA ${ }^{1}$ and Junji TAGAMI ${ }^{1,2}$ \\ ${ }^{1}$ Cariology and Operative Dentistry, Department of Restorative Sciences, Graduate School of Medical and Dental Sciences, Tokyo Medical and \\ Dental University, 1-5-45 Yushima, Bunkyo-ku, Tokyo 113-8549, Japan \\ ${ }^{2}$ Global Center of Excellence (GCOE) Program; International Research Center for Molecular Science in Tooth and Bone Diseases, Tokyo Medical \\ and Dental University, 1-5-45 Yushima, Bunkyo-ku, Tokyo 113-8549, Japan \\ Corresponding author, Hamid NURROHMAN; E-mail: hamid.nurrohman@gmail.com
}

\begin{abstract}
The purpose of this study was to investigate bond durability of MMA-based adhesives to root dentin in a simulated complete vertical root fracture (CVRF). The fractured fragments of human premolar root were reattached using Super-Bond C\&B (SB; Sun Medical), M-Bond or M-Bond II (MB or MB II; Tokuyama Dental). After storage for 1 day, 1 month, 6 months and 1 year, the reattached specimens were subjected to microtensile bond strength ( $\mu$ TBS) test at cervical and apical regions. Results showed that $\mu$ TBS was significantly higher to cervical dentin than to apical dentin in MB and MB II, but not SB $(p<0.05)$. Significant decrease in $\mu$ TBS was found for MB and MB II after 1 year, whereas no significant difference was found for SB $(p<0.05)$. Analysis of failure mode by SEM indicated differences over time. In conclusion, significant differences were found in the regional bond durability among MMA-based adhesives used to restore CVRF, that may lead to different clinical performances.
\end{abstract}

Keywords: Bond durability, Regional dentin, MMA-based adhesive resin, Complete vertical root fracture

\section{INTRODUCTION}

Complete vertical root fractures (CVRF) of endodontically treated teeth are frequently encountered in the dental practice $^{1)}$. Removal of tooth structure during endodontic and restorative treatments increases the risk of tooth fracture, with fatigue mechanisms mediating the fracture of root tissues over time ${ }^{2)}$. However, there are no reliable methods for treating the fractured teeth completely ${ }^{3-6)}$. Sugaya et $a l .^{7}{ }^{7}$ developed a new and promising method for CVRF by atraumatic intentional extraction, and rotational replantation of the tooth restored with an adhesive resin. Intentional extraction of the tooth fragments offers the advantage of enabling removal of the granulation tissue. In addition, rotational replantation brings the fracture line in contact with the healthy periodontal tissue ${ }^{8}$.

The complex structure of root dentin varies by its location; several studies have reported that dentin bondstrength of different adhesives was influenced by the region of the dentin substrate ${ }^{9,10)}$, and that the regional bond-strength durability was different between adhesives ${ }^{11}$. To date, the effect of regional structure of root dentin on the long-term bond strength of the repaired root has not been investigated.

4-methacryloxyethyl trimellitate anhydride/methyl methacrylate-tri-n-butyl borane resin (4-META/ MMA-TBB resin; Sun Medical, Moriyama, Japan) has been used to bond the CVRF segments because of its tolerance against blood contamination of the dentin surface $^{12)}$ and excellent bonding performance ${ }^{12,13)}$. Formation of a hybrid layer that consists of a molecularlevel mixture of adhesive polymers and dental hard tissues is recognized as one of the contributing factors to the high bond strength achieved by this material ${ }^{13,14)}$. However, the time required for application and polymerization of this material (more than $20 \mathrm{~min}$ ) appeared to be too long for bonding the fragments of the fractured root in the clinical situation.

In order to simplify the application procedures, MMA-based adhesive resins with self-etching primers either in two bottles or in a single bottle have been developed (M-Bond and M-Bond II; Tokuyama Dental, Tokyo, Japan). In the self-etching primer system, etching and priming steps are combined into a single application step, and the self-etching primer agent is not rinsed off after application. A self-curing resin layer is then applied directly on the treated surface. In addition to the simplified application procedure, these MMA adhesive resins have a shorter setting time and a longer handling time compared to the 4-META/MMA-TBB resin. However, the literature has reported conflicting results on bond strengths of some simplified systems to dentin ${ }^{15-17)}$, raising concerns over the durability of the interface achieved with these systems. Moreover, little information is available about the performance of the self-etching MMA-based adhesive resins used to reattach root fragments in CVRF.

The aim of the present study was to investigate bond durability of three MMA-based adhesive resins to different regions of root dentin in a simulated CVRF over a period of 1 year, by evaluating microtensile bond strength and failure analysis. The null hypothesis of this study was that the microtensile bond strengths and failure modes of the tested MMA-based adhesive resin systems were not affected by long-term water storage 
and dentin location.

\section{MATERIALS AND METHODS}

\section{Adhesive materials and teeth}

Three self-cured MMA-based adhesive resins, Super-Bond C\&B (SB; Sun Medical), M-Bond and M-Bond II (MB and MB II, Tokuyama Dental), were used in this study (Table 1). SB is a two-step acid-etching 4-META/MMA-TBB adhesive resin, while MB and MB II are self-etching systems.

Sixty-six human lower premolars with single root were used as bonding substrates. They were collected after the individuals' informed consent, and used according to a protocol approved by the Institutional Review Board of Tokyo Medical and Dental University. The teeth were stored in water at $4^{\circ} \mathrm{C}$ and used within one month after extraction. The teeth were randomly distributed into three groups according to the adhesive resins. Each tooth was sectioned approximately $1 \mathrm{~mm}$ below the cemento-enamel junction (CEJ) using a low-speed diamond saw (Isomet; Buehler, Lake Bluff, IL, USA) under water stream. The pulpal tissue was removed from root canal with a barbed broach. The root surfaces were then cleaned from of all remnants of periodontal ligament by scouring using a scalpel blade.

\section{Bonding procedures and bond strength test}

The outline of the microtensile bond strength ( $\mu$ TBS) test is schematically presented in Fig. 1. In order to provide sufficient bulk for handling, resin buildups were made on the buccal and lingual surfaces of the roots using Clearfil SE Bond (Kuraray Medical, Tokyo, Japan) as adhesive and 2-mm-thick increments of resin composite (Clearfil AP-X; Kuraray Medical).

Cervical and apical halves of each root were identified and painted with different colors on the composite surface. In order to simulate a CVRF, the roots were vertically sectioned at the middle in the mesio-distal direction to obtain 2 fragments. The dentin surface on each fragment was then lightly ground with 600-grit SiC paper under a water spray to create a standard smear layer, similar to the clinical treatment method, in which the smear layer was created by rotary instruments on the fracture lines ${ }^{18,19)}$.

Each pair of fragments obtained from the same tooth in each of the groups were then reattached using one of the three MMA-based adhesive resins; SB, MB and MB II according to the manufacturers' instructions. Immediately prior to setting (approximately $20 \mathrm{~min}$ for

Table 1 Adhesive materials used in this study

\begin{tabular}{|c|c|c|c|c|}
\hline $\begin{array}{l}\text { Material/Lot/ } \\
\text { Manufacturer }\end{array}$ & & Composition & $\mathrm{pH}$ & Application \\
\hline \multirow{4}{*}{$\begin{array}{l}\text { Super-Bond } \\
\text { C\&B; SK1 } \\
\text { Sun Medical; } \\
\text { Moriyama, Japan }\end{array}$} & Green activator (10-3) & $10 \%$ citric acid, $3 \% \mathrm{FeCl}_{3}$ & \multirow[t]{4}{*}{0.74} & \multirow{4}{*}{$\begin{array}{l}\text { Etch dentin with } 10-3 \text { solution for } \\
10 \mathrm{~s} \text {, rinse and air-dry } \\
\text { Powder : Liquid : Catalyst } \\
=1: 4: 1 \\
\text { Mixed for } 5 \mathrm{~s} \text {, applied to dentin } \\
\text { surface }\end{array}$} \\
\hline & Catalyst & TBB & & \\
\hline & Powder & PMMA & & \\
\hline & Liquid & MMA, 4-META & & \\
\hline \multirow{4}{*}{$\begin{array}{l}\text { M-Bond; X760532 } \\
\text { Tokuyama Dental; } \\
\text { Tokyo, Japan }\end{array}$} & Primer A & $\begin{array}{l}\text { Phosphoric acid monomers, } \\
\text { acetone }\end{array}$ & \multirow[t]{4}{*}{1.6} & \multirow{4}{*}{$\begin{array}{l}\text { Mixed equal amounts of Primer A } \\
\text { and } \mathrm{B} \text {, apply for } 30 \mathrm{~s} \text { and gently } \\
\text { air-dry for } 10 \mathrm{~s} \\
\text { Powder : Liquid }=1: 3 \\
\text { Mixed for } 10 \mathrm{~s} \text {, applied to dentin } \\
\text { surface }\end{array}$} \\
\hline & Primer B & $\begin{array}{l}\text { Water, acetone, borate } \\
\text { catalyst }\end{array}$ & & \\
\hline & Powder & PMMA, BPO & & \\
\hline & Liquid & $\begin{array}{l}\text { MMA, MAC-10, amine, } \\
\text { multifunctional } \\
\text { methacrylate }\end{array}$ & & \\
\hline \multirow[t]{3}{*}{$\begin{array}{l}\text { M-Bond II; 0090Y8 } \\
\text { Tokuyama Dental; } \\
\text { Tokyo, Japan }\end{array}$} & Primer & $\begin{array}{l}\text { Phosphoric acid monomer, } \\
\text { water, acetone, UDMA, } \\
\text { co-activator }\end{array}$ & \multirow[t]{3}{*}{1.7} & \multirow{3}{*}{$\begin{array}{l}\text { Apply primer for } 20 \mathrm{~s} \text { and gently } \\
\text { air-dry for } 10 \mathrm{~s} \\
\text { Powder : Liquid }=1: 3 \\
\text { Mixed for } 5 \mathrm{~s} \text {, applied to dentin } \\
\text { surface }\end{array}$} \\
\hline & Powder & PMMA, co-activator & & \\
\hline & Liquid & $\begin{array}{l}\text { MMA, UDMA, HEMA, } \\
\text { MTU-6, borate catalyst }\end{array}$ & & \\
\hline
\end{tabular}

TBB, tri-n-butyl borane; MMA, methyl methacrylate; 4-META, 4-methacryloxyethyl trimellitate anhydride; BPO, benzoyl peroxide; MAC-10, 10- methacryloyloxydecamethylene malonic acid; HEMA, 2-hydroxyethyl methacrylate; UDMA, urethane dimethacrylate; MTU-6, 6-methacryloxyhexyl 2-thiouracil-5-carboxylate. 

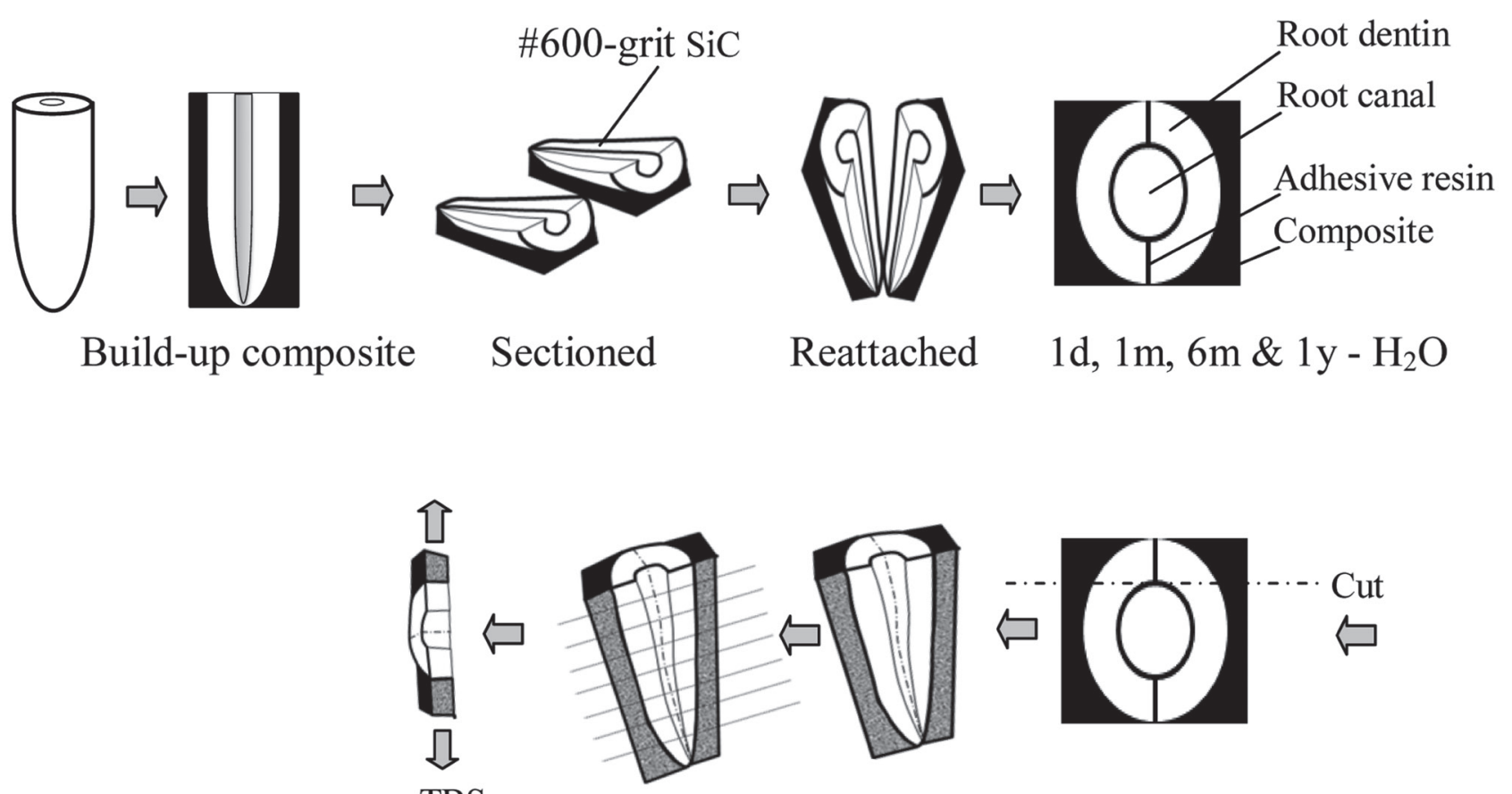

$\mu \mathrm{TBS}$

Fig. 1 Sample preparation of the $\mu$ TBS test setup.

SB and 10 min for MB and MB II), excess of the adhesive resin was carefully removed with a hand instrument ${ }^{18)}$. The reattached specimens were then placed in water maintained at $37^{\circ} \mathrm{C}$ for up to $1 \mathrm{y}$. The solution was changed daily and no preservative or antimicrobial agents were used ${ }^{20)}$. To prevent thermocycling effects, the water was heated to $37^{\circ} \mathrm{C}$ prior to changing it. After $1 \mathrm{~d}, 1 \mathrm{~m}, 6 \mathrm{~m}$ or $1 \mathrm{y}$, five premolars were used for $\mu$ TBS test. At each period, the specimens were longitudinally sectioned in a bucco-lingual direction from its central part, yielding two halves, each one containing the resin-bonded dentin interfaces. The resulting specimens were serially sectioned into beams with cross-sectional areas of $1 \mathrm{~mm}^{2}$, cut at right angles to the long axis of the root. Three beams were collected from each dentin region of each specimen, resulting in a total of 15 beams per period and dentin region $(n=15)$.

These specimens were then fixed to the testing jig of a handy-type universal testing machine (EZ-Test; Shimadzu, Kyoto, Japan) with a cyanoacrylate adhesive (Zapit; DVA, Anaheim, CA, USA) and subjected to microtensile bond strength testing at a crosshead speed of $1 \mathrm{~mm} / \mathrm{min}$. To determine the mode of failure, all specimens were immediately examined after fracture under a stereomicroscope (Nikon SMZ1000; Nikon, Tokyo, Japan) at a magnification of $40 \times$. Failure modes were categories as: (A) adhesive failure at the resin-dentin interface; (B) cohesive failure completely within the adhesive resin; (C) partially adhesive failure, where remnants of resin remained on the dentin surface; (D) cohesive failure in the demineralized or intact dentin.
Representative specimens for each failure mode were additionally examined by a scanning electron microscope (SEM) (JSM-5310LV; JEOL, Tokyo, Japan) to confirm the stereomicroscope observations. Prior to the SEM observations, the specimens were air-dried and sputtercoated with gold.

\section{SEM examination of the conditioned dentin surfaces}

The six remaining premolars were sectioned longitudinally in the bucco-lingual direction and a standard smear layer was created on the fractured dentin surfaces by wet grinding in the same way as for the specimens in the $\mu$ TBS test. Dentin specimens in SB group were conditioned using SB green activator $(10 \%$ citric acid with $3 \%$ ferric chloride: $10-3$ solution) for $10 \mathrm{~s}$, rinsed and air-dried. In $\mathrm{MB}$ and $\mathrm{MB}$ II groups, the specimens were treated with the self-etching primer of MB (Primer A and B) for $30 \mathrm{~s}$ or that of MB II (Primer) for $20 \mathrm{~s}$, respectively and gently air-dried. Immediately after conditioning, the surface was subjected to an ascending series of ethanol (30, 50, 70 and 95\%) for $1 \mathrm{~min}$ each. In case of MB and MB II, the specimens were further ultrasonically cleaned in absolute acetone for 1 min in order to completely dissolve the primer and dehydrate the specimens for SEM observation. After air-drying, the samples were coated with gold and examined using the SEM to observe surface texture and etching pattern.

\section{Statistics}

The $\mu$ TBS data of the three MMA-based adhesives to 
cervical or apical dentin after different storage time periods were statistically analyzed using a three-way ANOVA (adhesive material vs. dentin region vs. storage period). Separate two-way ANOVAs were also conducted within each material or within each storage time followed by Dunnett's T3 post-hoc tests. The statistical significance level was always set at $\alpha=0.05$.

\section{RESULTS}

\section{Microtensile bond strength testing}

Mean $\mu$ TBS are presented in Table 2. Three-way ANOVA revealed that each of the factors (adhesive material, dentin region, and storage period) had a significant effect on the $\mu$ TBS $(p<0.05)$; however, there were no significant interactions between the three factors $(p=0.857)$. Significant interactions were detected between adhesive material and dentin region $(p<0.05)$, and also between adhesive material and storage period $(p<0.05)$.

Separate two-way ANOVA within each material showed that unlike $\mathrm{SB}$, for both $\mathrm{MB}$ and $\mathrm{MB}$ II, the dentin region was a significant factor. Further analysis with multiple comparisons by Dunnett's T3 showed that in MB the $\mu$ TBS at $1 \mathrm{y}$ decreased significantly compared to $1 \mathrm{~d}(p<0.05)$. In MB II, the $\mu$ TBS at $6 \mathrm{~m}$ and $1 \mathrm{y}$ was significantly lower than that at $1 \mathrm{~d}(p<0.05)$. For $\mathrm{SB}$, there was no significant difference in $\mu$ TBS between $1 \mathrm{~d}$ and any other storage periods $(p>0.05)$.

Multiple comparisons between materials at each storage period indicated that there was no significant difference among materials at $1 \mathrm{~d}(p>0.05)$; however, at $1 \mathrm{y}$, SB showed significantly higher $\mu$ TBS compared to MB and MB II $(p<0.05)$, while MB and MB II were not significantly different ( $p>0.05)$.

Failure modes of all the test groups are summarized in Fig. 2 and representative SEM micrographs of each mode are presented in Fig. 3. For SB, cohesive failure in adhesive resin (mode B) was predominant in $1 \mathrm{~d}$ and $1 \mathrm{~m}$, for both cervical and apical dentin (Fig. 3a). Cohesive failure in demineralized dentin under the hybrid layer (mode D) appeared in low percentages at $6 \mathrm{~m}$ and $1 \mathrm{y}$ (Fig. 3b). Moreover, there was an increase in partial adhesive failure with a thin layer of adhesive resin remaining on the dentin surface (mode $\mathrm{C}$ ) at $6 \mathrm{~m}$ and $1 \mathrm{y}$. For MB, cohesive failure in adhesive resin cement (mode B) was the dominant failure mode during the experimental periods for cervical dentin, while adhesive failure mostly occurred for apical dentin. In this adhesive resin, failure mode $\mathrm{D}$ (cohesive failure in dentin) was not detected in any of the specimens. For MB II, most of the failures to regional dentin were found to be adhesive along the dentin surface (mode A) up to $1 \mathrm{y}$ (Figs. 3c and 3d). Similar to MB, no cohesive failure in dentin (mode D) was observed. Several defects (voids or blisters) were observed within the remnants of the cement for MB and MB II on the dentin surface after failure (Figs. 3c and 3e).

\section{SEM examination of the conditioned dentin surfaces}

The result of SEM examination of the dentin surface treated by SB, MB and MB II are shown in Figs. 4a to c. After the dentin was etched with 10-3 solution (SB), the smear layer and smear plugs appeared to be removed and the tubule orifices were completely exposed (Fig. 4a). SEM observation showed that the self-etching primers of MB or MB II had a similar effect on the dentin surface. The smear layer appeared to be demineralized, exposing collagen fibrils on the intertubular dentin surface. Some smear plugs were only partially removed, occasionally leaving smear debris in the tubules. Some tubules remained occluded in MB II specimens (Figs. 4b and c).

\section{DISCUSSION}

There is a growing demand for a reliable treatment method to deal vertical root fracture ${ }^{3-8)}$. In this study, a promising method ${ }^{7,8,18)}$ to reattach the root fragments in CVRF was investigated. Although this method is

Table $2 \mu$ TBS to human root dentin after different water storage periods

\begin{tabular}{|c|c|c|c|c|c|}
\hline Groups & Dentin region & $1 \mathrm{~d}$ & $1 \mathrm{~m}$ & $6 \mathrm{~m}$ & $1 \mathrm{y}$ \\
\hline \multirow{3}{*}{$\mathrm{SB}$} & Cervical & $23.2(7.5)$ & $27.4(8.2)$ & $25.3(3.7)$ & $21.0(6.6)$ \\
\hline & Apical & $24.6(7.9)$ & $27.7(4.3)$ & $26.0(2.7)$ & $22.1(5.2)$ \\
\hline & Total & $23.9(7.5)^{\mathrm{ab} \mathrm{A}}$ & $27.5(6.4)^{\mathrm{a} \mathrm{B}}$ & $25.6(3.2)^{\mathrm{a} \mathrm{D}}$ & $21.5(5.9)^{\mathrm{b} \mathrm{G}}$ \\
\hline \multirow{3}{*}{$\mathrm{MB}$} & Cervical* & $24.6(5.6)$ & $26.4(3.7)$ & $24.2(4.3)$ & $18.6(6.9)$ \\
\hline & Apical* & $22.5(3.8)$ & $25.2(5.2)$ & $22.1(3.4)$ & $12.8(5.1)$ \\
\hline & Total & $23.6(5.0)^{\mathrm{c} \mathrm{A}}$ & $25.8(4.5)^{\mathrm{c} \mathrm{B}}$ & $23.2(4.0)^{\mathrm{c} E}$ & $15.7(6.7)^{\mathrm{d} \mathrm{H}}$ \\
\hline \multirow{3}{*}{ MB II } & Cervical** $^{* *}$ & $22.8(4.2)$ & $20.8(4.8)$ & $18.7(2.8)$ & $14.8(4.0)$ \\
\hline & Apical** & $20.9(3.8)$ & $18.3(2.1)$ & $17.1(2.8)$ & $12.1(5.9)$ \\
\hline & Total & $21.9(4.1)^{\mathrm{e} A}$ & $19.6(3.9)^{\mathrm{ef} \mathrm{C}}$ & $18.0(2.9)^{\mathrm{f} \mathrm{F}}$ & $13.5(5.2)^{\mathrm{g} \mathrm{H}}$ \\
\hline
\end{tabular}

Means (SD) in MPa. $(n=15)$.

a-g Within each material, total values with the same lowercase letters showed no statistically significant difference $(p>0.05)$.

A-H At each time period, total values with the same capital letters showed no statistically significant difference ( $p>0.05)$.

$*, * *$ The region (cervical or apical) was a significant factor for within the adheive material $(p<0.05)$. 


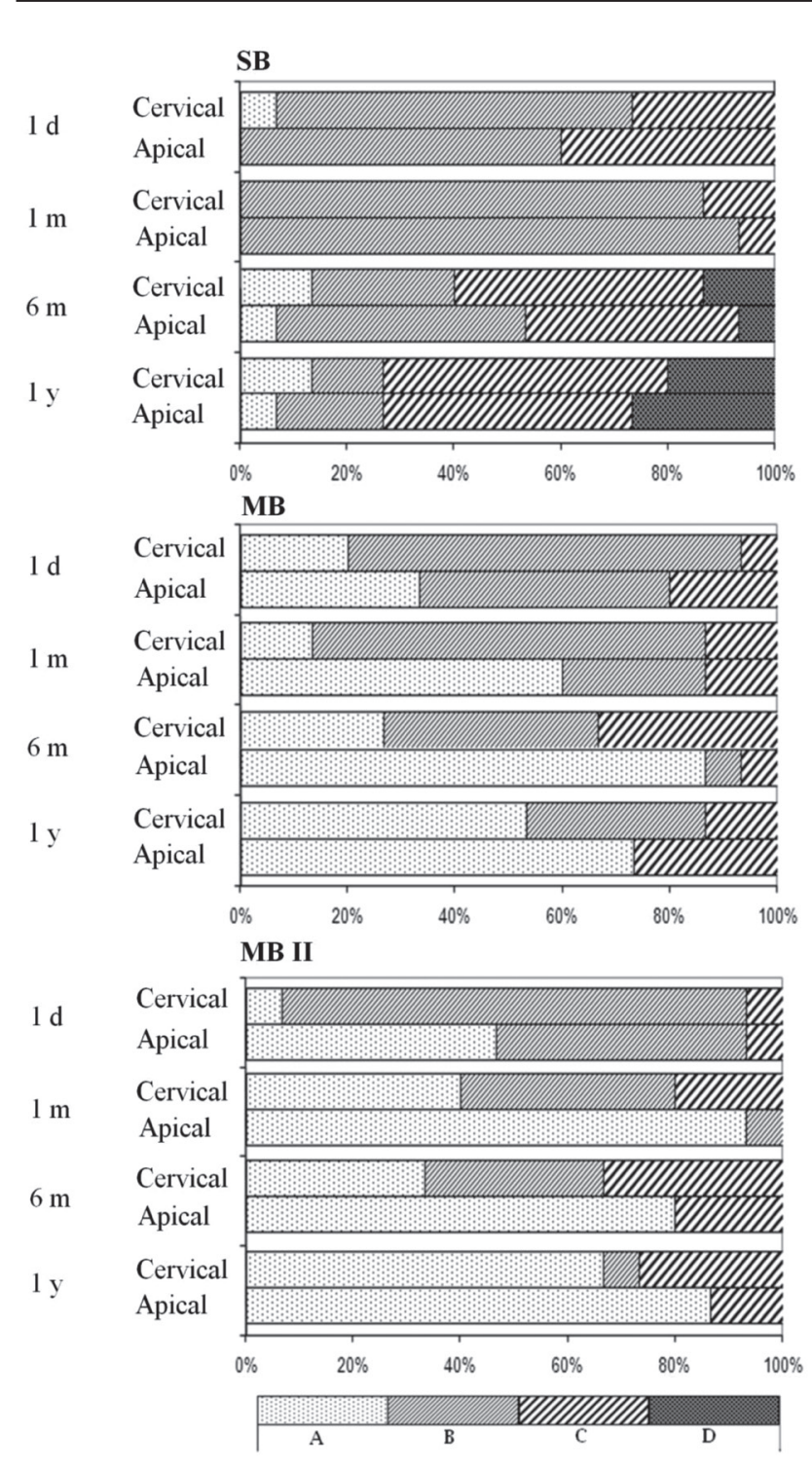

Fig. 2 Fracture mode distribution after tensile testing. A: Adhesive failure at the resin-dentin interface; B: Cohesive failure completely within the adhesive resin; C: Partial adhesive failure, where remnants of resin remained on the dentin surface; D: Cohesive failure in the demineralized dentin and intact dentin.

debatable and root resorption caused by ankylosis cannot be avoided ${ }^{21)}$, an immediate replantation and long-term maintenance of the natural tooth would be of great value to patients, avoiding advanced surgical procedures and financial costs resulting from advanced prosthetic replacement.

In this study, the fracture line was lightly polished to refresh the adhesion sites on dentin as suggested by Arikan et al. ${ }^{18)}$; however, it should be noted that in the clinical situation, as much healthy root dentin tissue as possible should be preserved while cleaning and the cement layer should be made as thin as possible by pushing the fragments together. Regeneration of cementum and periodontium can be expected when the space of the cement is small ${ }^{8,18)}$.

The tensile strength of root dentin is considered important in understanding not only the characteristics of root dentin but also the high occurrence of CVRF. Moreover, the fracture resistance of the repaired root in the long-term will impact the success of this treatment. A combination of the microtensile method developed by Sano et $a l .{ }^{22}$ and the CVRF reattachment technique enabled measurement and comparison of the regional bond strengths in the same tooth. In addition, the repaired specimens were stored in water for up to $1 \mathrm{y}$ to evaluate long-term performance.

In the present study, three MMA-based adhesives, including one acid-etching system (SB) and two self-etching systems (MB and MB II), were evaluated. Interestingly there was no statistically significant difference in $\mu$ TBS of SB between cervical versus apical dentin. It is known that in the cervical region, intrinsic dentin water content increases with increased tubule diameter and density (number $\left./ \mathrm{mm}^{2}\right)^{23}$. It was reported that the polymerization initiator in SB utilized oxygen and water to initiate radical polymerization of the resin monomers ${ }^{24)}$. Therefore, considering the stability of bond strength in SB within different regions and over time, it maybe stated that SB had a certain tolerance to the surface moisture or water content of dentinn ${ }^{23,25)}$. Moreover, tubule diameter and tubule density decrease from cervical to apical dentin ${ }^{26,27)}$. If resin tag formation was the only factor affecting the adhesion, the $\mu$ TBS would have decreased in the apical region. However, in both regions, etching with the 10-3 solution resulted in complete removal of the smear layer and exposure of the intertubular and circumferentially oriented collagen fibrils, allowing hybridization of dentin and resin tag formation $^{28)}$. These findings are in agreement with previous report which concluded that SB performed well in bonding to both superficial and deep dentin ${ }^{25}$. It is noteworthy that the MMA-based adhesive resin is hydrophobic; therefore, a very low water uptake is seen into the body of adhesive over time ${ }^{29}$. In this context, a long-term degradation of this material should involve the interface or the underlying dentin rather than the adhesive layer itself. While the $\mu \mathrm{TBS}$ of SB to dentin was stable over time, the failure modes showed a remarkable change. The location of the failure shifted from cohesive failure within the adhesive resin towards failure at the bottom of hybrid layer and underlying dentin. It was sugested that SB monomers did not fully diffuse through the collagen network after acid etching, and the unprotected collagen acted as pathway for hydrolytic degradation of the hybrid layer and change in failure mode ${ }^{20,30}$. Changing the storage solution might also induce the loss of calcium from the etched dentin, resulting in further exposure of the dentin collagen, which could have an important effect on the hydrolysis of unprotected collagen fibrils ${ }^{20)}$.

While the null hypothesis could be accepted for SB, 

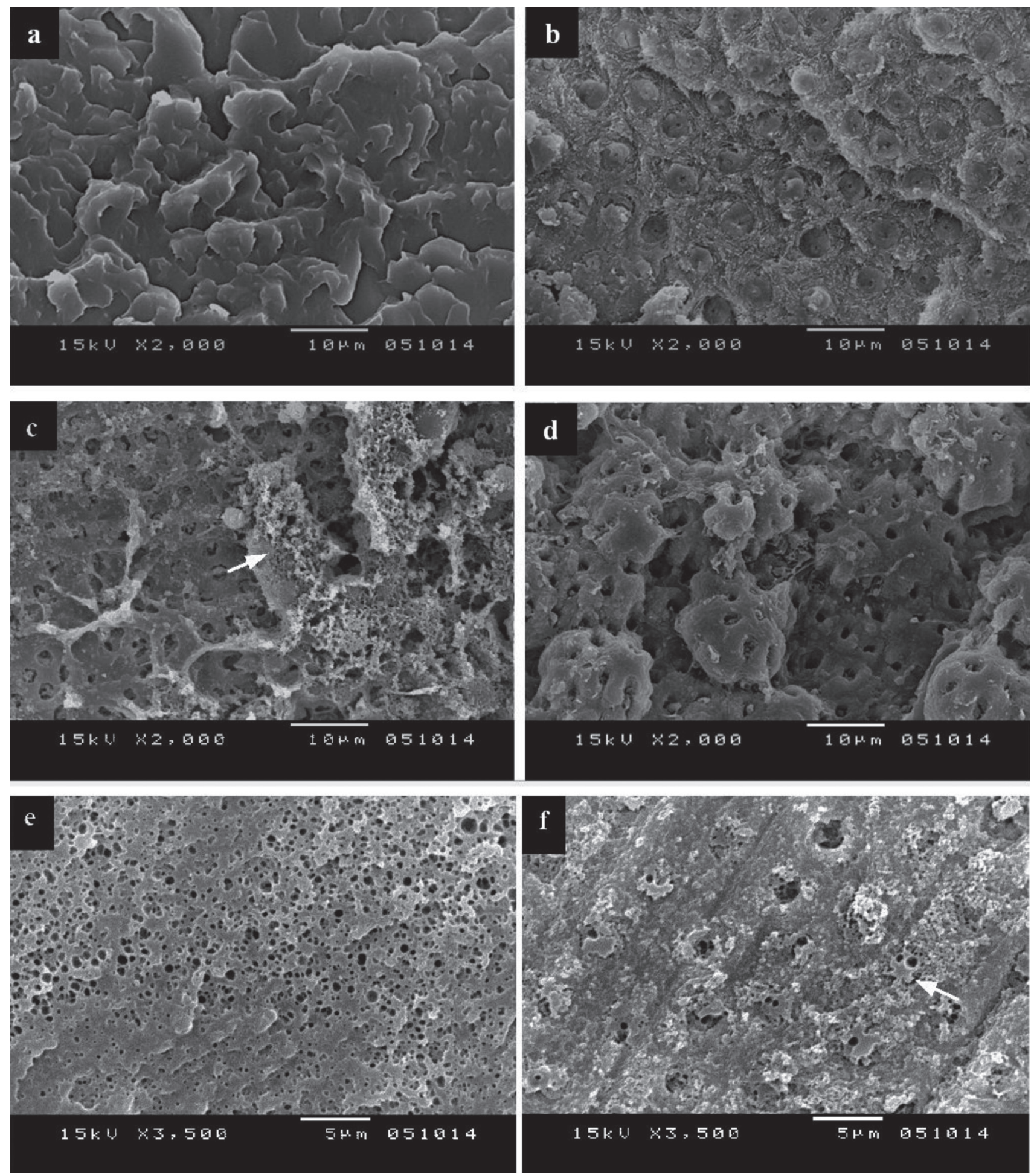

Fig. 3 SEM micrographs of the fractured surface at $\times 2,000$ (a-d) and $\times 3,500$ (e,f) magnifications. (a) SB at 1 m; the observed mode was cohesive failure within the adhesive resin. (b) SB at $6 \mathrm{~m}$; failure has occurred at the bottom of the hybrid layer. (c) MB II at $6 \mathrm{~m}$; adhesive failure at resin-dentin interface with remnants of a porous adhesive resin (arrow). (d) MB II at $1 \mathrm{y}$; adhesive failure can be observed at the interface of the adhesive resin and a superficially demineralized dentin. (e) MB at $1 \mathrm{y}$; cohesive failure within adhesive resin, numerous voids are observed within the material. (f) $\mathrm{MB}$ at $1 \mathrm{y}$; adhesive failure at the resin-dentin interface with small remnants of the resin (arrow). 

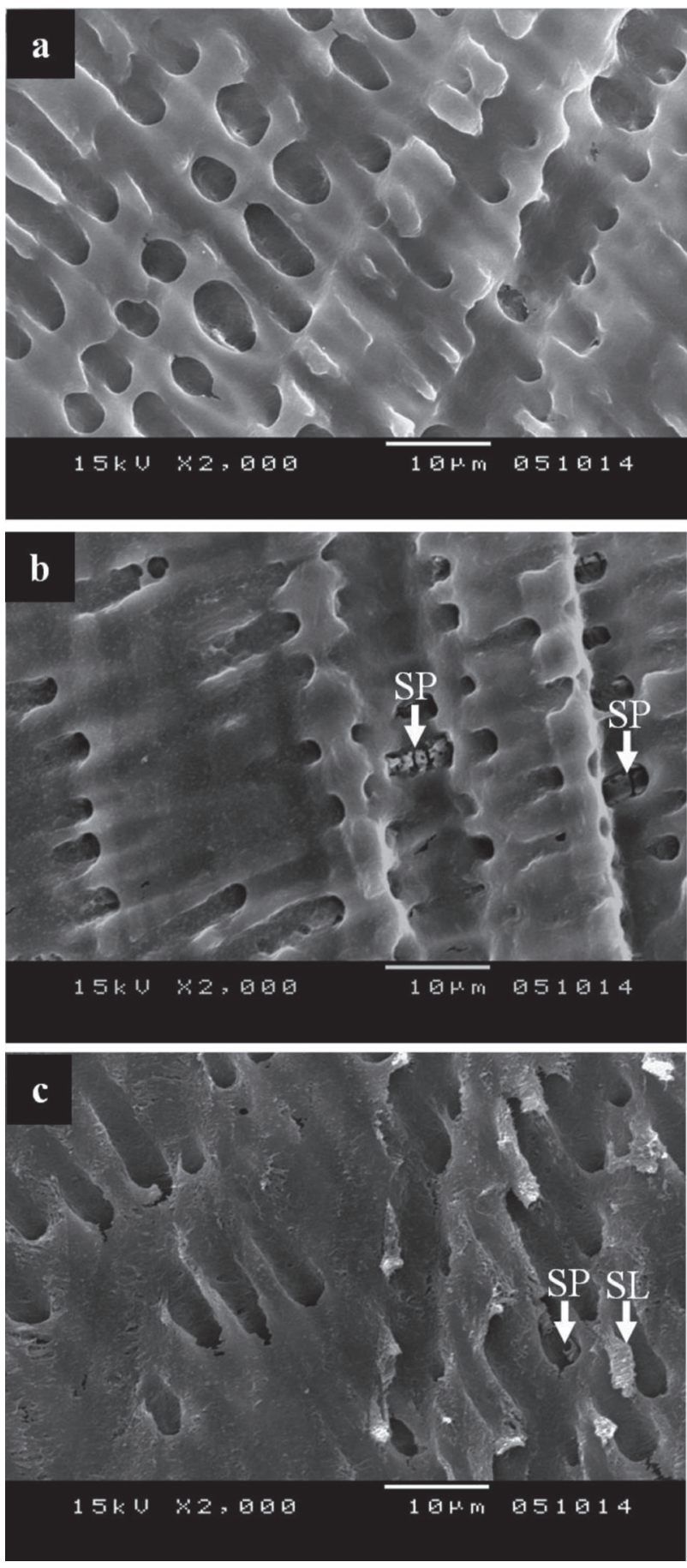

Fig. 4 SEM micrographs of conditioned dentin surfaces, as the bonding substrates in the three groups. (a) Dentin surface etched with $10 \%$ citric acid with $3 \%$ ferric chloride (group SB); the smear layer and smear plugs appeared to be completely removed and the tubule orifices were opened wide. (b) Dentin surface treated with self-etching primer of MB; the smear layer was removed with small traces of the smear plugs (SP) remaining. (c) Dentin surface treated with self-etching primer of MB II; residual smear layer (SL) and smear plug (SP) partially obliterating the dentinal tubules orifices are observed. it was rejected for $\mathrm{MB}$ and $\mathrm{MB}$ II, as the $\mu$ TBS values were decreased by storage and the $\mu$ TBS was significantly influenced by the dentin region; bond strength to cervical dentin was higher than that to apical dentin for both materials. It was speculated that the higher $\mu$ TBS in cervical dentin was due to increased permeability of dentin to resin penetration and an increased crosssectional area in the cervical region ${ }^{31}$. In addition, apical dentin is more sclerotic or transparent than the other region depending on the age ${ }^{32}$. Formation of sclerotic dentin begins at the apical end of the root and often extending into the coronal dentin ${ }^{33)}$. In this region, not only the tubules are filled with acid-resistant whitlockite minerals ${ }^{9}$, but also the intertubular dentin seems to be more acid resistant ${ }^{34)}$. The self-etching primers of $\mathrm{MB}$ (pH 1.6) and MB II ( $\mathrm{pH}$ 1.7), with a mild etching capacity demineralize dentin only partially and parts of smear layers and smear plugs remain on the dentin (Figs. 4b and c), hampering the diffusion of monomers into the apical dentin ${ }^{35}$ and forming a thin interfacial zone in this region. Unlike SB speciemns which tended to fail within demineralized dentin overtime, in MB and MB II frequent adhesive failures were observed, which generally became more prevalent especially in apical dentin, confirming that the resin-dentin interface was the weak-link in these groups.

A significant decrease was found in $\mu$ TBS of both self-etching systems among the different experimental periods. Numerous voids were seen along the fractured interfaces of both materials (Figs. 3c and 3e). Several reports exist on the incompatibility between chemically activated resin composites combined with acidic monomers ${ }^{36,37)}$. Despite the improved initiator system of $\mathrm{MB}$ and $\mathrm{MB} \mathrm{II}^{38}$, the voids may form due to the low conversion degree of primer components and/or excessive water in the formulation ${ }^{39)}$. A high concentration of hydrophilic components such as phosphoric acid monomers in both MB and MB II primers could lead to an increased water sorption, and consequently, decreased hydrolytic stability of the interface ${ }^{40)}$. In addition, apart from the primer, the body of these resin cements is composed of an MMA-based resin. It was reported that upon effective polymerization, a hydrophobic MMA-based resin showed lower water sorption when compared to most methacrylate-based resin adhesives that contained high amount of hydrophilic solvents ${ }^{29,41)}$. However, the stability and water sorption of the new mixtures of MMA and other monomers as in the formulation of $\mathrm{MB}$ and MB II are not known.

While micromechanical interlocking of resin into etched and primed dentin was historically considered to be the most important mechanism of bonding to dentin $^{13,14)}$, with mild self-etching primers, a stable chemical interaction between acidic monomers and the hydroxyapatite minerals remaining within the substrate may provide additional benefits to achieve a strong durable bond ${ }^{42)}$. However, one should be aware that in order to take full advantage of the mild self-etching primer systems, adhesive systems with balanced formulations are necessary. Further research is 
warranted on the development and evaluation of self-etching primer based self-cure adhesive resin cements.

\section{CONCLUSIONS}

Based on our results it can be concluded that the long-term bond strengths of three MMA-based adhesive resins to different regions of root dentin in a simulated CVRF after aging in water was material dependent. The $\mu$ TBS of SB was stable over time and not affected by dentin region, whereas $\mathrm{MB}$ and MB II showed a lower bond strength to apical dentin and a significant decrease over 1 y period.

\section{ACKNOWLEDGMENTS}

This work was supported, in part, by the grant from the Japanese Ministry of Education, Global Center of Excellence program, International Research Center for Molecular Science in Tooth and Bone Diseases at Tokyo Medical and Dental University and by grant-in-aid for scientific research from the Japan Society for the Promotion of Science (JSPS No. 19209059-05).

\section{REFERENCES}

1) Tamse A. Vertical root fractures in endodontically treated teeth: diagnostic signs and clinical management. Endod Topics 2006; 13: 84-94.

2) Kishen A. Mechanisms and risk factors for fracture predilection in endodontically treated teeth. Endod Topics 2006; 13: 57-83.

3) Pitts DL, Natkin E. Diagnosis and treatment of vertical root fractures. J Endod 1983; 9: 338-346.

4) Trope M, Rosenberg ES. Multidisciplinary approach to the repair of vertically fractured teeth. J Endod 1992; 18: 460-463.

5) Selden HS. Repair of incomplete vertical root fractures in endodontically treated teeth -in vivo trials. J Endod 1996; 22: 426-429.

6) Dederich $\mathrm{DN}$. $\mathrm{CO}_{2}$ laser fusion of a vertical root fracture. J Am Dent Assoc 1999; 130: 1195-1199.

7) Sugaya T, Kawanami M, Noguchi H, Kato H, Masaka N. Periodontal healing after bonding treatment of vertical root fracture. Dent Traumatol 2001; 17: 174-179.

8) Kawai K, Masaka N. Vertical root fracture treated by bonding fragments and rotational replantation. Dent Traumatol 2002; 18: $42-45$

9) Yoshiyama M, Sano H, Ebisu S, Tagami J, Ciucchi B, Carvalho RM, Johnston MH, Pashley DH. Regional strengths of bonding agents to cervical sclerotic root dentin. J Dent Res 1996; 75: 1404-1413.

10) Pereira PN, Okuda M, Sano H, Yoshikawa T, Burrow MF, Tagami J. Effect of intrinsic wetness and regional difference on dentin bond strength. Dent Mater 1999; 15: 46-53.

11) De Munck J, Mine A, Vivan Cardoso M, De Almeida Neves A, Van Landuyt KL, Poitevin A, Van Meerbeek B. Effect of dentin location and long-term water storage on bonding effectiveness of dentin adhesives. Dent Mater J 2011; 30: 7-13.

12) Miles DA, Anderson RW, Pashley DH. Evaluation of the bond strength of dentin bonding agents used to seal resected root apices. J Endod 1994; 20: 538-541.

13) Nakabayashi N, Kojima K, Masuhara E. The promotion of adhesion by the infiltration of monomers into tooth substrates.
J Biomed Mater Res 1982; 16: 265-273.

14) Nakabayashi N, Nakamura M, Yasuda N. Hybrid layer as a dentin-bonding mechanism. J Esthet Dent 1991; 3: 133-138.

15) Van Meerbeek B, Yoshida Y, Snauwaert J, Hellemans L, Lambrechts P, Vanherle G, Wakasa K, Pashley DH. Hybridization effectiveness of a two-step versus three-step smear layer removing adhesive material examined correlatively by TEM and AFM. J Adhes Dent 1999; 1: 7-23.

16) Bouillaguet S, Gysi P, Wataha JC, Ciucchi B, Cattani M, Godin C, Meyer JM. Bond strength of composite to dentin using conventional, one-step, and self-etching adhesive systems. J Dent 2001; 29: 55-61.

17) Swift EJ. Enamel-dentin bonding. J Esthet Restor Dent 2003; 15: 203.

18) Arikan F, Franko M, Gurkan A. Replantation of a vertically fractured maxillary central incisor after repair with adhesive resin. Int Endod J 2008; 41: 173-179.

19) Ogata M, Harada N, Yamaguchi S, Nakajima M, Tagami J. Effect of self-etching primer vs phosphoric acid etchant on bonding to bur-prepared dentin. Oper Dent 2002; 27: 447-454.

20) Kitasako Y, Burrow MF, Nikaido T, Tagami J. The influence of storage solution on dentin bond durability of resin cement. Dent Mater 2000; 16: 1-6.

21) Panzarini SR, Gulinelli JL, Poi WR, Sonoda CK, Pedrini D, Brandini DA. Treatment of root surface in delayed tooth replantation: a review of literature. Dent Traumatol 2008; 24: 277-282.

22) Sano H, Shono T, Sonoda H, Takatsu T, Ciucchi B, Carvalho R, Pashley DH. Relationship between surface area for adhesion and tensile bond strength - evaluation of a microtensile bond test. Dent Mater 1994; 10: 236-240.

23) Tagami J, Tao L, Pashley DH. Correlation among dentin depth, permeability, and bond strength of adhesive resins. Dent Mater 1990; 6: 45-50.

24) Okamoto Y, Takahata K, Saeki K. Studies on the behaviour of partially oxidized tributylborane as a radical initiator for methyl methacrylate (MMA) polymerization. Chem Lett 1998; 27: 1247-1248.

25) Tao L, Tagami J, Pashley DH. Pulpal pressure and bond strengths of SuperBond and Gluma. Am J Dent 1991; 4: 73-76.

26) Carrigan PJ, Morse DR, Furst ML, Sinai IH. A scanning electron microscopic evaluation of human dentinal tubules according to age and location. J Endod 1984; 10: 359-363.

27) Mjör IA, Nordahl I. The density and branching of dentinal tubules in human teeth. Arch Oral Biol 1996; 41: 401-412.

28) Pashley DH, Ciucchi B, Sano H, Carvalho RM, Russell CM. Bond strength versus dentin structure: a modelling approach. Arch Oral Biol 1995; 40: 1109-1118.

29) Unemori M, Matsuya Y, Matsuya S, Akashi A, Akamine A. Water absorption of poly(methyl methacrylate) containing 4-methacryloxyethyl trimellitic anhydride. Biomaterials 2003; 24: 1381-1387.

30) Kitasako Y, Burrow MF, Nikaido T, Tagami J. Long-term tensile bond durability of two different 4-META containing resin cements to dentin. Dent Mater 2002; 18: 276-280.

31) El Zohairy AA, De Gee AJ, Mohsen MM, Feilzer AJ. Effect of conditioning time of self-etching primers on dentin bond strength of three adhesive resin cements. Dent Mater 2005; 21: 83-93.

32) Kinney JH, Nalla RK, Pople JA, Breunig TM, Ritchie RO. Age-related transparent root dentin: mineral concentration, crystallite size, and mechanical properties. Biomaterials 2005; 26: 3363-3376

33) Micheletti Cremasco M. Dental histology: study of aging processes in root dentine. Boll Soc Ital Biol Sper 1998; 74: 19-28.

34) Van Meerbeek B, Braem M, Lambrechts P, Vanherle G. Morphological characterization of the interface between resin 
and sclerotic dentine. J Dent 1994; 22: 141-146.

35) Yoshiyama M, Urayama A, Kimochi T, Matsuo T, Pashley DH. Comparison of conventional vs self-etching adhesive bonds to caries-affected dentin. Oper Dent 2000; 25: 163-169.

36) Sanares AM, Itthagarun A, King NM, Tay FR, Pashley DH. Adverse surface interactions between one-bottle light-cured adhesives and chemical-cured composites. Dent Mater 2001; 17: 542-556.

37) Swift EJ Jr, Perdigao J, Combe EC, Simpson CH 3rd, Nunes MF. Effects of restorative and adhesive curing methods on dentin bond strengths. Am J Dent 2001; 14: 137-140.

38) Tay FR, King NM, Suh BI, Pashley DH. Effect of delayed activation of light-cured resin composites on bonding of all-in-one adhesives. J Adhes Dent 2001; 3: 207-225.
39) Cadenaro M, Antoniolli F, Sauro S, Tay FR, Di Lenarda R, Prati C, Biasotto M, Contardo L, Breschi L. Degree of conversion and permeability of dental adhesives. Eur J Oral Sci 2005; 113: 525-530.

40) Yiu CK, King NM, Pashley DH, Suh BI, Carvalho RM, Carrilho MR, Tay FR. Effect of resin hydrophilicity and water storage on resin strength. Biomaterials 2004; 25: 5789-5796.

41) Hashimoto M, Tay FR, Sano H, Kaga M, Pashley DH. Diffusion-induced water movement within resin-dentin bonds during bonding. J Biomed Mater Res B Appl Biomater 2006; 79: 453-458.

42) Yoshida Y, Nagakane K, Fukuda R, Nakayama Y, Okazaki M, Shintani H. Comparative study on adhesive performance of functional monomers. J Dent Res 2004; 83: 454-458. 